\title{
Prevalence, predictors and outcomes of potential drug-drug interactions in left ventricular failure: considerable factors for quality use of medicines
}

\author{
Inamul Haq ${ }^{1}$, Mohammad Ismail ${ }^{\oplus 1^{*}}$, Fahadullah Khan', \\ Qasim Khan ${ }^{1}$, Zahid Ali ${ }^{1}$, Sidra Noor ${ }^{1}$ \\ ${ }^{1}$ Department of Pharmacy, University of Peshawar, Khyber Pakhtunkhwa, Pakistan
}

\begin{abstract}
Hospitalized patients with left ventricular failure (LVF) are at high risk for potential drug-drug interactions (pDDIs) and its related adverse effects owing to multiple risk factors such as old age, comorbidities and polypharmacy. This cross-sectional study conducted in two tertiary care hospitals aim to identify frequency, levels and predictors of pDDIs in LVF patients. Data about patients' demographic, hospital stay, medication therapy, sign/symptoms and laboratory test results were collected for 385 patients with LVF. Micromedex Drug-Reax ${ }^{\circledR}$ was used to screen patients' medication profiles for pDDIs. Overall prevalence and severity-wise prevalence of pDDIs were identified. Chisquare test was performed for comparative analysis of various variables. Logistic regression was applied to determine the odds-ratios (OR) for predictors of pDDIs. The prevalence of pDDIs was $96.4 \%(n=371)$. Overall 335 drug-interacting pairs were detected, which were presented in a total of 2870 pDDIs. Majority of pDDIs were of major- (48.9\%) and moderate-severity (47.5\%). Logistic regression analysis shows significant association of $>6$ all types of pDDIs with $>12$ drugs as compared with $\leq 8$ drugs $(O R=16.5 ; p=<0.001)$. Likewise, there was a significant association of $>4$ majorpDDIs with men as compared with female $(\mathrm{OR}=1.9 ; \mathrm{p}=0.007)$ and $>12$ drugs as compared with $\leq 8$ drugs $(\mathrm{OR}=10.9 ; \mathrm{p}=<0.001)$. Hypotension $(\mathrm{n}=57)$, impaired renal function $(23)$ and increased blood pressure (22) were the most frequent adverse outcomes associated with pDDIs. This study shows high prevalence of pDDIs in LVF patients. Majority of pDDIs were of major- and moderate-severity. Male patients and those prescribed greater number of medicines were more exposed to major-pDDIs.
\end{abstract}

Keywords: Left ventricular failure. Heart diseases. Potential drug-drug interactions. Drug interactions. Patients safety. Rational drug use.

\section{INTRODUCTION}

Left Ventricular Failure (LVF) represents a subset of heart failure (HF) (Rosenkranz et al., 2016). HF is recognized as a major health concern (Go et al., 2014) because of severely frequent adverse health outcomes and its extensive financial implications (Sanchez-

*Correspondence: M. Ismail, Department of Pharmacy, University of Peshawar, Peshawar, Khyber Pakhtunkhwa, Pakistan. Phone: +92-919216750. Fax: +92-91-9218131. E-mail: ismailrph@uop.edu.pk
Fidalgo et al., 2017). HF affects around $2 \%$ of the adult population worldwide, (Metra, Teerlink, 2017) making it a leading cause of hospitalization (Alvarez et al., 2017). Hospitalized patients with LVF (Rosenkranz et al., 2016) are at high risk for developing potential drug-drug interactions (pDDIs) (Bykov, Gagne, 2017) owing to its underlying risk factors, advancing age, multiple comorbidities (Alvarez et al., 2017), polypharmacy (Ismail et al., 2017; Stough, Patterson, 2017) and/or combinations of these factors (Meid et al., 2017). 
Pharmacotherapy is the most common mode of therapeutic management of the LVF. This comprises of a complex regimen (polypharmacy); beta-blockers, angiotensin converting enzyme inhibitors, diuretics, ionotropic agents, the aldosterone antagonist and more recently, the angiotensin receptor neprilysin inhibitors (Stough, Patterson, 2017), is the currently widely applied strategy of treatment (Stough, Patterson, 2017). The published data demonstrated that LVF trumps polypharmacy among other disorders like diabetes, chronic obstructive pulmonary disease (COPD) and asthma in community (Ledwidge et al., 2004).

Polypharmacy is a major contributing risk factor for drug-drug interactions (DDIs). The incidence of DDIs in patients with HF ranges from $13 \%$ for 2 drugs to $82 \%$ for $\geq 7$ drugs (Roblek et al., 2016). About $16-26 \%$ of adverse drug reactions (ADRs) related hospital admissions in patients with HF are due to DDIs (Roblek et al., 2016; Roblek et al., 2014) which leads to increased hospitalization, excessive treatment cost and impaired quality of life (Roblek et al., 2014). DDIs may either surge to increased toxicity or reduced therapeutic efficacy (Cruciol-Souza, Thomson, 2006b; Moura et al., 2012).

Few studies have addressed this issue in HF; however, these studies have several gaps and limitations (Roblek et al., 2014; Straubhaar, Krahenbuhl, Schlienger, 2006). A Slovenian study primarily focused at patients with HF and COPD addressed this issue, however it was not exclusively performed in patients with LVF. Moreover, it merely reported the prevalence of pDDIs (Roblek et al., 2014). Whereas, another study from Switzerland, although was exclusively performed in HF patients, but it only reported the prevalence and nature of pDDIs (Straubhaar, Krahenbuhl, Schlienger, 2006). Therefore, there is a need for explicit work in patients with LVF particularly in developing countries, including Pakistan because of scarce literature.

An appraisal of the literature reveals no research that poses a specific insight into all aspects of pDDIs in patients with LVF. These aspects include predictors of pDDIs, documentation levels suggesting support of pDDIs through literature, understanding of the widespread interacting drug pairs and assessment of associated clinical relevance based on patients' clinical characteristics (sign/symptoms, blood pressure) and related laboratory/diagnostic tests (blood urea nitrogen, serum creatinine, serum potassium, serum sodium, prothrombin time (PT), activated partial thromboplastin time (APTT), international normalized ratio (INR), hemoglobin and platelet concentration), which can optimize the quality of prescribing in patients with LVF. Forgoing in view, we aim to identify the frequency, levels and predictors of pDDIs along with its associated clinical relevance. Moreover, we aim to develop a list of most frequent pDDIs in hospitalized patient with LVF.

\section{PATIENTS AND METHODS}

\section{Setting and Design}

This cross-sectional retrospective study was performed in the cardiology wards of two major tertiary care hospitals of a provincial capital. This study included hospitalized patients' medication profiles $(n=385)$ diagnosed with LVF, $>18$ years of age and either gender, for a period of one-year from May 2015 to April 2016. Patients' profiles lacking relevant data required for this study were excluded.

\section{Ethical Considerations}

This study was approved by the institutional ethics committee.

\section{Data collection}

Permission was obtained from the hospitals' administration in order to access patients' medication profiles. Data regarding patient's demographic, hospital admission, medication therapy, signs, symptoms and laboratory/diagnostic test results were collected.

\section{Data analysis}

Micromedex Drug-Reax ${ }^{\circledR}$ (Micromedex, 2018) was used to screen patients' medication profile for pDDIs. It is an online screening tool in which all prescribed medications are entered, and in return a list of all pDDIs is generated as an output, based on the most recent available literature on drug interactions. We used Micromedex Drug-Reax ${ }^{\circledR}$ because of its well-documented precision, completeness, sensitivity and specificity (Vonbach et al., 2008). This drug interaction screening tool classifies pDDIs on the basis of their severity and the available scientific evidence (Roblek et al., 2015). The severitylevels of pDDIs and their description is as follows: 
Contraindicated: The co-prescription of the drug pair is not advised owing its proven risk.

Major: The co-prescription of the drug pair may lead to life-threating adverse events, requiring prompt medical intervention.

Moderate: The co-prescription of the drug pair may deteriorate patient's clinical well-being, requiring prompt changes in medication therapy.

Minor: The co-prescription of the drug pair may result in limited clinically relevant untoward events, however no major modifications in the drug therapy is required.

Furthermore, the pDDIs are also categorized into the following groups based on available scientific evidence: Excellent: Interaction arising from co-prescription of the drug pair has been confirmed by controlled studies.

Good: Interaction arising from co-prescription of the drug pair has been suggested by studies, but wellcontrolled studies are scarce.

Fair: Interaction arising from co-prescription of the drug pair has poor documentary evidence for the presence of any clinically relevant untoward effect.

\section{Statistical Analysis}

Quantitative variables like patient's age, hospital stay, number of prescribed medications and number of pDDIs per patient are presented as median and interquartile range (IQR). The pDDIs are classified categorically with regard to their frequencies and percentages. However, gender, prevalence of pDDIs, number of pDDIs per patient, severity levels and documentation levels are presented in the form of frequencies and percentages. Chi-square test was performed to identify the differences among patients' characteristics with $>6$ all types of pDDIs and $>4$ major-pDDIs. Logistic regression analysis was applied in order to identify associations of presence of $>6$ pDDIs with patients' gender, age, hospital stay and prescribed medications. Moreover, association of $>4$ major-pDDIs exposure to above mentioned variables was also identified. Exposure to $>6$ pDDIs of any severity and exposure to $>4$ major-DDIs were the dependent variables in the model. Variables that were taken as predictors of pDDIs include gender, age, hospital stay and number of prescribed medications. For each predictor, odds ratio (OR) and 95\% confidence interval (CI) were determined. Initially univariate logistic regression analysis was carried out followed by the performance of multivariate analysis for the variables with significant univariate p-values. In this study, p-value of 0.05 or less was considered statistically significant. SPSS-v21 was used for statistical analysis. The clinical relevance of the most frequent (top ten drug interacting pairs) was identified on the basis of signs/symptoms and laboratory test results.

\section{RESULTS}

\section{Patients' characteristics}

Of total 385 patients, $52.5 \%$ were female and $47.5 \%$ were male. The median age was 60 years, where majority of patients $(64.2 \%)$ had $>55$ years of age. The median hospital stay was 4 days with high proportion of patients $(42.9 \%)$ having hospital stay of 4-6 days, followed by $41 \%$ patients with $\leq 3$ days of hospital stay. Patients received a median of 11 drugs, $40.5 \%$ patients received 9-12 drugs, followed by $>12$ drugs prescribed to $39.5 \%$ patients as shown in Table I.

TABLE I - General characteristics of study subjects

\begin{tabular}{lc}
\hline Characteristics & Patients: $\mathbf{n}(\%)$ \\
\hline Gender & $183(47.5)$ \\
Male & $202(52.5)$ \\
Female & \\
\hline Age (Years) & $25(6.5)$ \\
$\leq 40$ & $113(29.4)$ \\
$41-55$ & $247(64.2)$ \\
$>55$ & 60 \\
Median & $50-70$ \\
\hline IQR & \\
\hline
\end{tabular}

\section{Hospital stay (Days)}

$\leq 3$

4-6

$165(42.9)$

$>6$

$62(16.1)$

Median

4

IQR $3-5.5$ 
TABLE I - General characteristics of study subjects

\begin{tabular}{lc}
\hline Characteristics & Patients: $\mathbf{n}(\%)$ \\
\hline Prescribed medications & \\
$\leq 8$ & $77(20)$ \\
$9-12$ & $146(40.5)$ \\
$>12$ & $152(39.5)$ \\
Median & 11 \\
IQR & $9-14$ \\
\hline
\end{tabular}

$\mathrm{IQR}=$ Interquartile range.

\section{Frequencies of pDDls}

Frequencies of potential drug-drug interactions are presented in Figure 1. Of total 385 patients, 96.4\% patients had one or more pDDI(s). Nearly $91 \%$ patients had at least one major-pDDI, similarly $91 \%$ had at least one moderate-pDDI. Whereas, $13.5 \%$ patients had at least one minor-pDDI and $3.4 \%$ patients had one or more contraindicated pDDI(s). Majority of patients had pDDIs with good $(90.1 \%)$ and fair $(90.1 \%)$ documented evidence. While, $40 \%$ patients had pDDIs with excellent documented evidence. Moreover, majority of patients (51.2\%) had $>6$ pDDIs, followed by $29.1 \%$ patients having 4-6 pDDIs. While, only 3.6\% patients had no pDDIs.

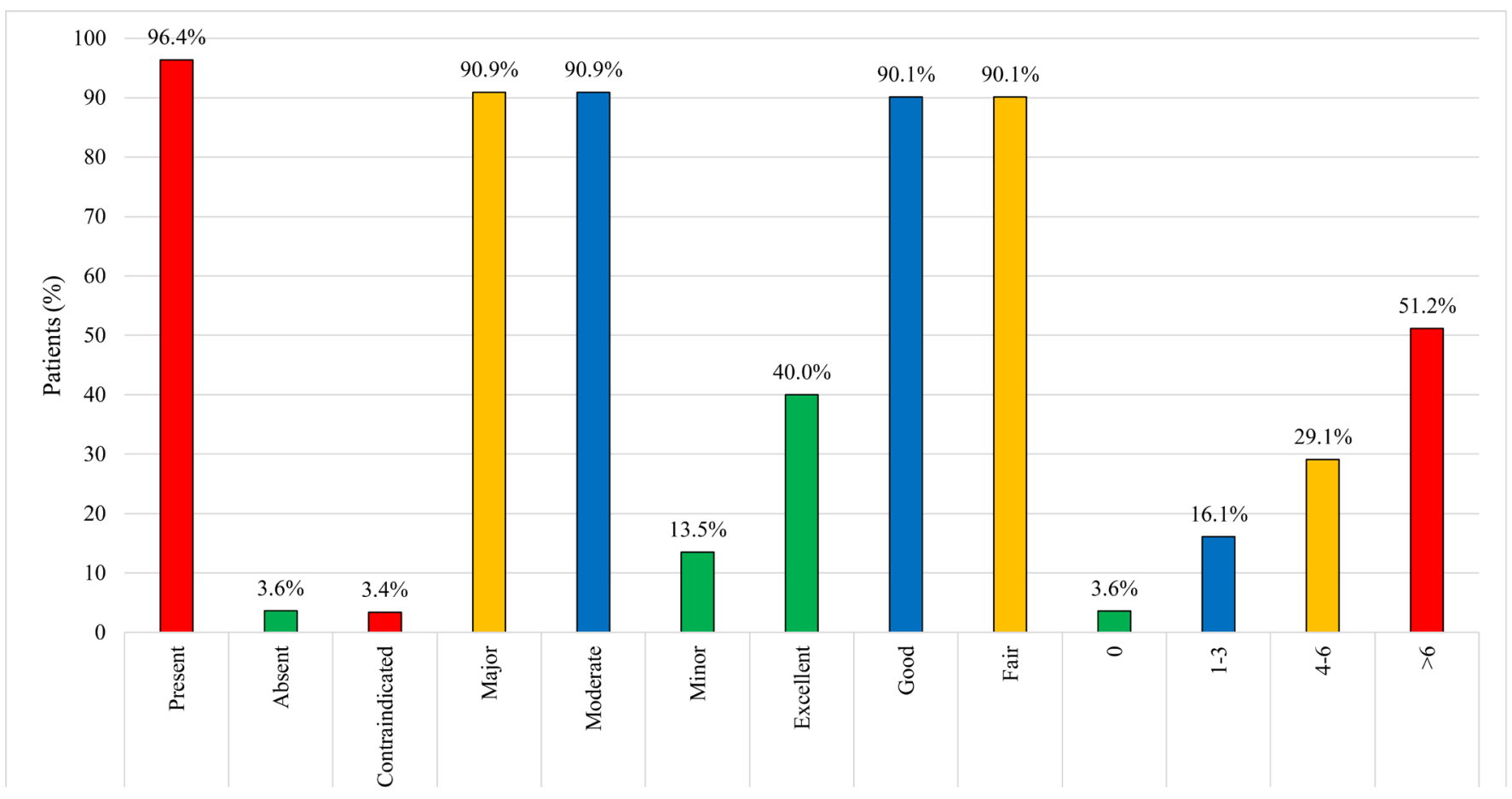

FIGURE 1 - Frequencies of pDDIs = Potential drug-drug interactions.

Number of pDDIs per patient: Median $=7($ Inter quartile range $=4-10)$ 


\section{Levels of pDDls}

Figure 2 illustrates levels of pDDIs. Overall 335 drug interacting pairs were detected, which were presented in total of 2870 pDDIs. The identified pDDIs were categorized on the basis of severity-type and documented evidence. Of 2870 pDDIs, 1405 (48.9\%) were of major-severity and $1365(47.5 \%)$ were of moderate severity; whereas $47 \%$ and $44.9 \%$ were of good and fair documented evidence, respectively. Of the 335 drug interacting pairs $177(52.8 \%)$ were of majorseverity, while 133 (39.7\%) were of moderate-severity, whereas, $184(54.9 \%)$ and $112(33.4 \%)$ were of fair and good documented evidence, respectively.

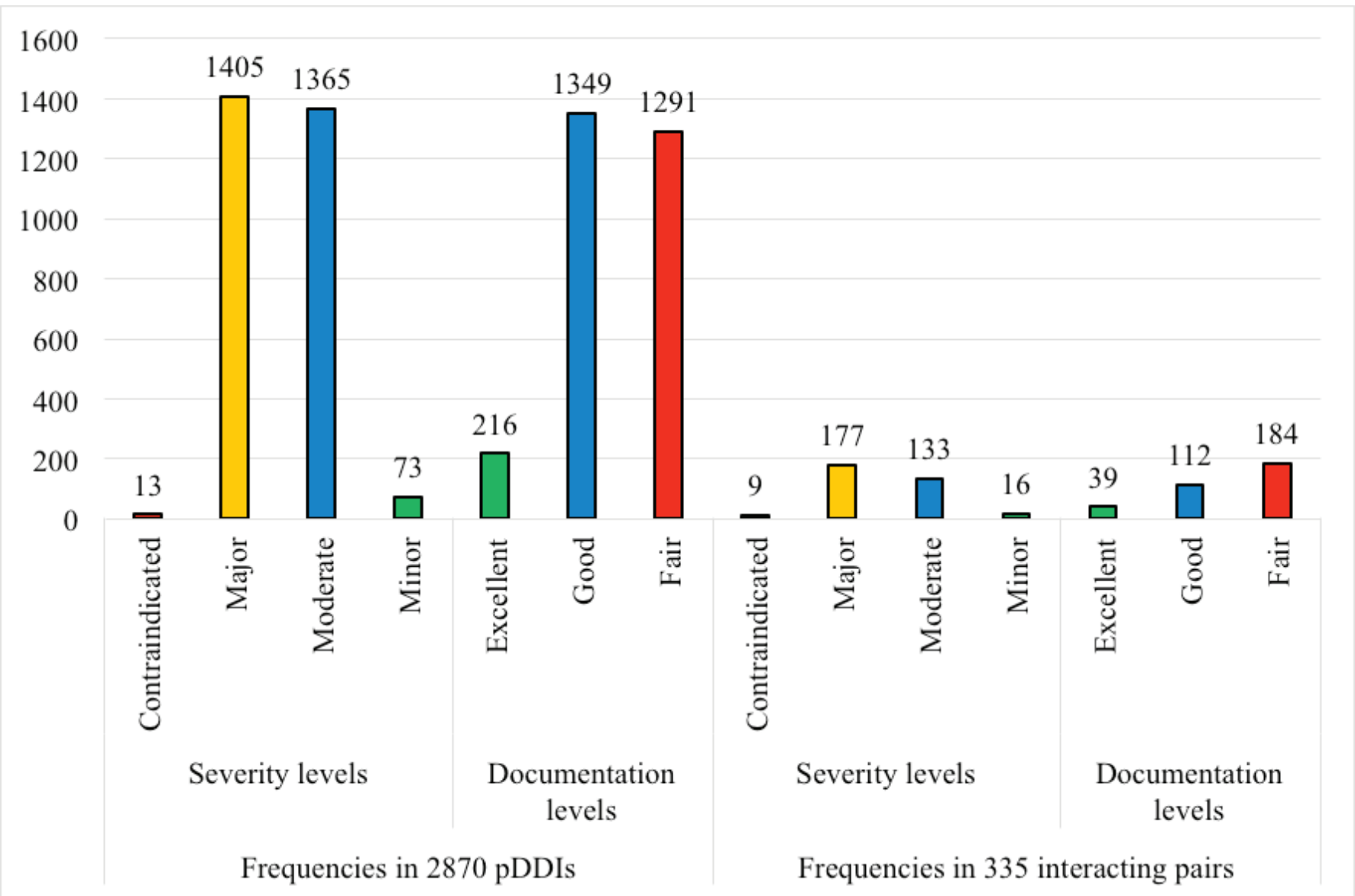

FIGURE 2 - Levels of identified pDDIs.

pDDIs $=$ Potential drug-drug interactions.

\section{Predictors of pDDIs}

Table II presents exposure to $>6$ all types of pDDIs and $>4$ major-pDDIs stratified with respect to patients' characteristics such as gender, age, hospital stay and prescribed medications along with their comparative analysis. Significant differences were observed for prescribed medicines with $>6$ all types of pDDIs.
Whereas, differences between gender, age and hospital stay were not significant. On the other hand, significant differences were estimated for gender and prescribed medications with $>4$ major-pDDIs. While, no significant differences were present with age and hospital stay. In addition, significant differences were noted with number of prescribed medications for excellent and good documentation. 
TABLE II - Exposure to potential drug-drug interactions and documentation levels, stratified according to patients' characteristics

\begin{tabular}{|c|c|c|c|c|c|c|c|c|c|c|}
\hline \multirow{2}{*}{ Variables } & \multicolumn{2}{|c|}{$\begin{array}{l}>6 \text { all types of } \\
\text { pDDIs: } n(\%)\end{array}$} & \multirow{2}{*}{ p-value } & \multicolumn{2}{|c|}{$\begin{array}{c}\text { >4 Major- } \\
\text { pDDIs: n }(\%)\end{array}$} & \multirow{2}{*}{ p-value } & $\begin{array}{c}\text { Excellent } \\
\text { pDDIs: n (\%) } \\
\end{array}$ & \multirow{2}{*}{ p-value } & $\begin{array}{c}\text { Good } \\
\text { pDDIs: } \mathbf{n}(\%)\end{array}$ & \multirow{2}{*}{ p-value } \\
\hline & Absent & Present & & Absent & Present & & Absent Present & & Absent Present & \\
\hline
\end{tabular}

\section{Gender}

\begin{tabular}{|c|c|c|c|c|c|c|c|c|c|}
\hline Male & $89(23.1 \%)$ & $94(24.4)$ & NS & $117(30.4)$ & $66(17.1)$ & 0.008 & $112(29.1) 71(18.4)$ & NS & $13(3.4) \quad 170(44.2)$ \\
\hline Female & $99(25.7)$ & $103(26.8)$ & & $154(40)$ & $48(12.5)$ & & 119 (30.9) 83 (21.6) & & $25(6.5) \quad 177(46)$ \\
\hline
\end{tabular}

\section{Age (Years)}

\begin{tabular}{|c|c|c|c|c|c|c|c|c|c|c|c|}
\hline$\leq 40$ & $14(3.6)$ & $11(2.9)$ & NS & 19 (4.9) & $6(1.6)$ & NS & $18(4.7)$ & $7(1.8)$ & NS & $1(0.3)$ & $24(6.2)$ \\
\hline $41-55$ & 48 (12.5) & 65 (16.9) & & $82(21.3)$ & $31(8.1)$ & & 63 (16.4) & $50(13)$ & & $9(2.3)$ & $104(27)$ \\
\hline$>55$ & $126(32.7)$ & $121(31.4)$ & & $170(44.2)$ & 77 (20) & & $150(39)$ & $97(25.2)$ & & $28(7.3)$ & $219(56.9)$ \\
\hline
\end{tabular}

\section{Hospital stay (Days)}

\begin{tabular}{|c|c|c|c|c|c|c|c|c|c|c|c|}
\hline$\leq 3$ & $85(22.1)$ & 73 (19) & NS & $117(30.4)$ & $41(10.6)$ & NS & $103(26.8)$ & $55(14.3)$ & NS & $14(3.6)$ & $144(37.4)$ \\
\hline $4-6$ & $79(20.5)$ & $86(22.3)$ & & $113(29.4)$ & $52(13.5)$ & & $91(23.6)$ & 74 (19.2) & & 19 (4.9) & $146(37.9)$ \\
\hline$>6$ & $24(6.2)$ & $38(9.9)$ & & 41 (10.6) & $21(5.5)$ & & 37 (9.6) & $25(6.5)$ & & $5(1.3)$ & 57 (14.8) \\
\hline
\end{tabular}

\section{Prescribed medicines}

\begin{tabular}{|c|c|c|c|c|c|c|c|c|c|c|c|}
\hline$\leq 8$ & 64 (16.6) & $13(3.4)$ & $<0.001$ & $71(18.4)$ & $6(1.6)$ & $<0.001$ & $59(15.3)$ & $18(4.7)$ & $<0.001$ & $15(3.9)$ & $62(16.1)$ \\
\hline $9-12$ & $85(22.1)$ & $71(18.4)$ & & $120(31.2)$ & $36(9.4)$ & & $105(27.3)$ & $51(13.2)$ & & $13(3.4)$ & $143(37.1)$ \\
\hline$>12$ & $39(10.1)$ & $113(29.4)$ & & $80(20.8)$ & $72(18.7)$ & & $67(17.4)$ & $85(22.1)$ & & $10(2.6)$ & $142(36.9)$ \\
\hline
\end{tabular}

pDDIs $=$ potential drug-drug interactions.

Table III represents the results of univariate logistic regression analysis for exposure to $>6$ all types of pDDIs and $>4$ major-pDDIs. In comparison with $\leq 3$ days of hospital stay, the risk of $>6$ all types of pDDIs increases by 1.8 times in patients with $>6$ days of hospital stay $(p=0.045)$. Similarly, the risk of $>6$ all types of pDDIs is 4.1 times higher in patients prescribed 9-12 drugs $(p=<0.001)$ and 14.3 times higher in patients taking $>12$ drugs $(p=<0.001)$ as compared with patients taking $\leq 8$ drugs. Whereas, no 
significant association was estimated for differences between gender and age groups. The risk of $>4$ majorpDDIs is 1.8 times higher in male patients $(p=0.009)$ as compared with female patients. Similarly, the risk increases by 3.6 times in patients prescribed 9-12 drugs $(\mathrm{p}=0.007)$ and 10.6 times in patients prescribed $>12$ drugs $(\mathrm{p}=<0.001)$ as compared with $\leq 8$ drugs. Logistic regression for $\mathrm{pDDIs}$ of good documentation showed significant association with 9-12 prescribed drugs $(p=0.02)$ and $>12$ prescribed drugs $(p=0.005)$, while, significant association was observed for pDDIs of excellent documentation with $>12$ prescribed drugs $(\mathrm{p}=<0.001)$.

The results of multivariate logistic regression analysis are presented in Table IV. In comparison with $\leq 8$ prescribed drugs, the risk of $>6$ all types of pDDIs is 4.5 times higher in patients taking 9-12 drugs $(p=<0.001)$ and 16.5 times in patients taking $>12$ drugs $(p=<0.001)$. Whereas, no significant association was observed between differences in hospital stay. For $>4$ major-pDDIs, the risk is 1.9 times higher in male patients $(p=0.007)$ as compared with female patients. Similarly, the risk of $>4$ major-pDDIs is 3.5 times higher in patients prescribed 9-12 drugs $(\mathrm{p}=0.008)$ and 10.9 times in patients taking $>12$ drugs $(p=<0.001)$ as compared with $\leq 8$ drugs. Likewise, the odds ratios were significant for pDDIs of excellent documentation with $>12$ prescribed drugs $(p=<0.001)$ and similarly for pDDIs of good documentation with $>12$ prescribed drugs $(\mathrm{p}=0.005)$.

TABLE III - Univariate logistic regression analysis based on exposure to $>6$ pDDIs, $>4$ Major-pDDIs and documentation levels

\begin{tabular}{|c|c|c|c|c|c|c|c|c|c|}
\hline & \multicolumn{2}{|r|}{$\frac{>6 \text { pDDIs }}{95 \% \text { CI p-value }}$} & OR & 95\% CI p-value & OR & $95 \% \mathrm{CI}$ & p-value & OR & $95 \%$ CI p-value \\
\hline
\end{tabular}

\section{Gender}

\begin{tabular}{|c|c|c|c|c|c|c|c|c|c|c|c|c|}
\hline \multirow{2}{*}{$\begin{array}{l}\text { Female } \\
\text { Male }\end{array}$} & \multicolumn{3}{|c|}{ Reference } & \multicolumn{3}{|c|}{ Reference } & \multicolumn{3}{|c|}{ Reference } & \multicolumn{3}{|c|}{ Reference } \\
\hline & 1 & $0.7-1.5$ & 0.9 & 1.8 & $1.2-2.8$ & 0.009 & 0.9 & $0.6-1.4$ & 0.6 & 1.8 & $0.9-3.7$ & 0.09 \\
\hline
\end{tabular}

Age (Years)

\begin{tabular}{|c|c|c|c|c|c|c|c|c|c|c|c|c|}
\hline \multirow{2}{*}{$\begin{array}{l}\leq 40 \\
41-55\end{array}$} & \multicolumn{3}{|c|}{ Reference } & \multicolumn{3}{|c|}{ Reference } & \multicolumn{3}{|c|}{ Reference } & \multicolumn{3}{|c|}{ Reference } \\
\hline & 1.7 & $0.7-4.1$ & 0.2 & 1.2 & $0.4-3.3$ & 0.7 & 2 & $0.8-5.3$ & 0.1 & 0.5 & $0.06-4$ & 0.5 \\
\hline$>55$ & 1.2 & $0.5-2.8$ & 0.6 & 1.4 & $0.6-3.7$ & 0.5 & 1.7 & $0.7-4$ & 0.3 & 0.3 & $0.04-2.5$ & 0.3 \\
\hline
\end{tabular}

\section{Hospital stay (Days)}

\begin{tabular}{|c|c|c|c|c|c|c|c|c|c|c|c|c|}
\hline$\leq 3$ & \multicolumn{3}{|c|}{ Reference } & \multicolumn{3}{|c|}{ Reference } & \multicolumn{3}{|c|}{ Reference } & \multicolumn{3}{|c|}{ Reference } \\
\hline $4-6$ & 1.3 & $0.8-2$ & 0.3 & 1.3 & $0.8-2.1$ & 0.3 & 1.5 & $1-2.4$ & 0.07 & 0.7 & $0.4-1.5$ & 0.4 \\
\hline
\end{tabular}


TABLE III - Univariate logistic regression analysis based on exposure to $>6$ pDDIs, $>4$ Major-pDDIs and documentation levels

\begin{tabular}{|c|c|c|c|c|c|c|c|c|c|c|c|c|}
\hline \multirow{2}{*}{ Variables } & \multicolumn{3}{|c|}{$>6$ pDDIs } & \multicolumn{3}{|c|}{ >4 Major-pDDIs } & \multicolumn{3}{|c|}{ Excellent pDDIs } & \multicolumn{3}{|c|}{ Good pDDIs } \\
\hline & OR & $95 \%$ CI & p-value & OR & $95 \%$ CI & p-value & OR & $95 \% \mathrm{CI}$ & p-value & OR & $95 \%$ CI & p-value \\
\hline$>6$ & 1.8 & $1-3.4$ & 0.045 & 1.5 & $0.8-2.8$ & 0.2 & 1.3 & $0.7-2.3$ & 0.4 & 1.1 & $0.4-3.2$ & 0.8 \\
\hline
\end{tabular}

\section{Prescribed medicines}

\begin{tabular}{|c|c|c|c|c|c|c|c|c|c|c|c|c|}
\hline \multirow{2}{*}{$\begin{array}{l}\leq 8 \\
9-12\end{array}$} & \multicolumn{3}{|c|}{ Reference } & \multicolumn{3}{|c|}{ Reference } & \multicolumn{3}{|c|}{ Reference } & \multicolumn{3}{|c|}{ Reference } \\
\hline & 4.1 & $2.1-8.1$ & $<0.001$ & 3.6 & $1.4-8.8$ & 0.007 & 1.6 & $0.8-3$ & 0.1 & 2.7 & $1.2-5.9$ & 0.02 \\
\hline$>12$ & 14.3 & $7.1-28.7$ & $<0.001$ & 10.6 & $4.4-26$ & $<0.001$ & 4.2 & $2.2-7.7$ & $<0.001$ & 3.4 & $1.5-8$ & 0.005 \\
\hline
\end{tabular}

pDDIs $=$ potential drug-drug interactions $; \mathrm{OR}=$ odds ratio $\mathrm{CI}=$ confidence interval.

TABLE IV - Multivariate logistic regression analysis based on exposure to $>6$ pDDIs and $>4$ Major-pDDIs

\begin{tabular}{|c|c|c|c|c|c|c|c|c|c|c|c|c|}
\hline \multirow{2}{*}{ Variables } & \multicolumn{3}{|c|}{$>6$ pDDIs } & \multicolumn{3}{|c|}{ >4 Major pDDIs } & \multicolumn{3}{|c|}{ Excellent pDDIs } & \multicolumn{3}{|c|}{ Good pDDIs } \\
\hline & OR & $95 \% \mathrm{CI}$ & p-value & OR & $95 \%$ CI & p-value & OR & $95 \%$ CI & p-value & OR & $95 \%$ CI & p-value \\
\hline
\end{tabular}

\section{Gender}

Female

Male

\begin{tabular}{ll}
\multicolumn{2}{c}{ Reference } \\
\hline $1.9 \quad 1.2-3 \quad 0.007$
\end{tabular}

\begin{tabular}{|c|c|c|c|c|}
\hline & & \multicolumn{3}{|c|}{ Reference } \\
\hline & - & 1.8 & $0.9-3.7$ & 0.1 \\
\hline
\end{tabular}

\section{Hospital stay (Days)}

$\leq 3$

4-6

$>6$

Prescribed medicines

$\leq 8$

$9-12$

$>12$

\begin{tabular}{ll}
\multicolumn{2}{c}{ Reference } \\
\hline $4.5 \quad 2.2-9 \quad<0.001$
\end{tabular}

\begin{tabular}{ccc}
\multicolumn{3}{c}{ Reference } \\
\hline $3.5 \quad 1.4-8.7 \quad 0.008$
\end{tabular}

\begin{tabular}{ccc}
\multicolumn{3}{c}{ Reference } \\
\hline 1.6 & $0.8-3$ & 0.2
\end{tabular}

\begin{tabular}{ccc}
\multicolumn{3}{c}{ Reference } \\
\hline 2.6 & $1.2-5.8$ & 0.02 \\
3.4 & $1.4-8$ & 0.005
\end{tabular}

$\mathrm{pDDIs}=$ potential drug-drug interactions $; \mathrm{OR}=$ odds ratio $\mathrm{CI}=$ confidence interval. 


\section{Wide spread interacting drug combinations}

The most frequently detected pDDIs are listed in Table $\mathrm{V}$ along with their severity and documentation levels. Potential adverse outcomes of these interactions include reduced therapeutic effectiveness, risk of bleeding, nephrotoxicity, hypotension, digoxin toxicity, electrolytes disturbance, increased blood pressure and hypoglycemia.

TABLE V - Most frequently identified interactions, their levels and potential adverse outcome

\begin{tabular}{|c|c|c|c|c|}
\hline Interacting pairs ${ }^{\mathrm{a}}$ & $\begin{array}{c}\text { Frequency } \\
\text { (No of patients) }\end{array}$ & Severity & Documentation & $\begin{array}{c}\text { Potential adverse } \\
\text { outcome }\end{array}$ \\
\hline Aspirin -- Furosemide & 237 & Major & Good & $\begin{array}{c}\text { Reduced diuretic } \\
\text { effectiveness and } \\
\text { possible nephrotoxicity }\end{array}$ \\
\hline Aspirin -- Clopidogrel & 189 & Major & Fair & Increased risk of bleeding. \\
\hline Aspirin -- Nitroglycerin & 172 & Moderate & Good & $\begin{array}{l}\text { Increase in nitroglycerin } \\
\text { concentrations and } \\
\text { additive platelet } \\
\text { function depression. }\end{array}$ \\
\hline Aspirin -- Spironolactone & 137 & Major & Good & $\begin{array}{c}\text { Reduced diuretic } \\
\text { effectiveness, } \\
\text { hyperkalemia, or possible } \\
\text { nephrotoxicity. }\end{array}$ \\
\hline Furosemide -- Ramipril & 132 & Moderate & Good & $\begin{array}{l}\text { Postural hypotension } \\
\text { (first dose). }\end{array}$ \\
\hline Digoxin -- Furosemide & 112 & Moderate & Fair & $\begin{array}{l}\text { Increased risk of } \\
\text { digoxin toxicity } \\
\text { (nausea, vomiting, and } \\
\text { cardiac arrhythmias). }\end{array}$ \\
\hline Aspirin -- Ramipril & 101 & Moderate & Fair & $\begin{array}{l}\text { Decreased Ramipril } \\
\text { effectiveness. }\end{array}$ \\
\hline Clopidogrel -- Enoxaparin & 92 & Major & Fair & Increased risk of bleeding. \\
\hline Ramipril -- Spironolactone & 80 & Major & Good & Hyperkalemia. \\
\hline Aspirin -- Bisoprolol & 79 & Moderate & Good & Increased blood pressure. \\
\hline Aspirin -- Insulin & 70 & Moderate & Fair & $\begin{array}{l}\text { Increased risk of } \\
\text { hypoglycemia. }\end{array}$ \\
\hline
\end{tabular}


TABLE V - Most frequently identified interactions, their levels and potential adverse outcome

\begin{tabular}{|c|c|c|c|c|}
\hline Interacting pairs ${ }^{\mathrm{a}}$ & $\begin{array}{c}\text { Frequency } \\
\text { (No of patients) }\end{array}$ & Severity & Documentation & $\begin{array}{c}\text { Potential adverse } \\
\text { outcome }\end{array}$ \\
\hline Aspirin -- Digoxin & 62 & Major & Fair & $\begin{array}{l}\text { Increased serum } \\
\text { concentration of } \\
\text { digoxin; prolonged } \\
\text { half-life of digoxin. }\end{array}$ \\
\hline Digoxin -- Spironolactone & 61 & Major & Good & Increased digoxin exposure \\
\hline Aspirin -- Carvedilol & 46 & Moderate & Good & Increased blood pressure. \\
\hline Atorvastatin -- Clopidogrel & 42 & Moderate & Excellent & $\begin{array}{c}\text { Reduced plasma } \\
\text { concentrations of } \\
\text { Clopidogrel active } \\
\text { metabolite. }\end{array}$ \\
\hline Albuterol -- Furosemide & 40 & Moderate & Fair & $\begin{array}{l}\text { ECG changes or } \\
\text { hypokalemia. }\end{array}$ \\
\hline Insulin -- Ramipril & 39 & Moderate & Fair & $\begin{array}{l}\text { Increased risk of } \\
\text { hypoglycemia. }\end{array}$ \\
\hline Clopidogrel -- Omeprazole & 35 & Major & Excellent & $\begin{array}{l}\text { Reduction in clinical } \\
\text { efficacy of Clopidogrel } \\
\text { and increased risk } \\
\text { for thrombosis. }\end{array}$ \\
\hline Furosemide -- Morphine & 31 & Moderate & Fair & $\begin{array}{l}\text { Decreased efficacy } \\
\text { of diuretics. }\end{array}$ \\
\hline Bisoprolol -- Insulin & 27 & Moderate & Good & $\begin{array}{l}\text { Hypoglycemia or } \\
\text { hyperglycemia; } \\
\text { decreased symptoms } \\
\text { of hypoglycemia. }\end{array}$ \\
\hline Clopidogrel -- Esomeprazole & 26 & Major & Excellent & $\begin{array}{c}\text { Reduced plasma } \\
\text { concentrations of } \\
\text { Clopidogrel active } \\
\text { metabolite. }\end{array}$ \\
\hline Digoxin -- Omeprazole & 24 & Moderate & Good & $\begin{array}{l}\text { Increased risk of digoxin } \\
\text { toxicity (nausea, vomiting, } \\
\text { and arrhythmias). }\end{array}$ \\
\hline Bisoprolol -- Digoxin & 23 & Moderate & Good & $\begin{array}{l}\text { Increased risk of } \\
\text { bradycardia and possible } \\
\text { digitalis toxicity. }\end{array}$ \\
\hline
\end{tabular}


TABLE V - Most frequently identified interactions, their levels and potential adverse outcome

\begin{tabular}{|c|c|c|c|c|}
\hline Interacting pairs ${ }^{\mathrm{a}}$ & $\begin{array}{c}\text { Frequency } \\
\text { (No of patients) }\end{array}$ & Severity & Documentation & $\begin{array}{c}\text { Potential adverse } \\
\text { outcome }\end{array}$ \\
\hline $\begin{array}{l}\text { Aminophylline } \\
\text {-- Furosemide }\end{array}$ & 23 & Minor & Fair & $\begin{array}{l}\text { Altered theophylline } \\
\text { concentrations. }\end{array}$ \\
\hline Aspirin -- Glimepiride & 21 & Major & Fair & $\begin{array}{l}\text { Increased risk of } \\
\text { hypoglycemia. }\end{array}$ \\
\hline Carvedilol -- Digoxin & 21 & Major & Fair & $\begin{array}{l}\text { Increased digoxin } \\
\text { concentrations; } \\
\text { increased risk of } \\
\text { complete heart block. }\end{array}$ \\
\hline Aspirin -- Calcium & 19 & Moderate & Fair & $\begin{array}{l}\text { Decreased salicylate } \\
\text { effectiveness. }\end{array}$ \\
\hline Aspirin -- Ranitidine & 18 & Minor & Excellent & $\begin{array}{l}\text { Reduced salicylate plasma } \\
\text { levels and decreased } \\
\text { antiplatelet effect of aspirin. }\end{array}$ \\
\hline Carvedilol -- Insulin & 18 & Moderate & Good & $\begin{array}{l}\text { Hypoglycemia or } \\
\text { hyperglycemia; } \\
\text { decreased symptoms } \\
\text { of hypoglycemia. }\end{array}$ \\
\hline Insulin -- Moxifloxacin & 17 & Major & Fair & $\begin{array}{l}\text { Changes in blood } \\
\text { glucose and increased } \\
\text { risk of hypoglycemia } \\
\text { or hyperglycemia. }\end{array}$ \\
\hline
\end{tabular}

a Of total 335 drug interacting pairs, the 30 most frequent drug interacting pairs are given in this table.

${ }^{\mathrm{b}}$ The frequency in this column represent the number of patients exposed to the given interaction.

\section{Clinical relevance}

Table VI represents clinical findings (signs, symptoms and laboratory test results) and monitoring/ management guidelines (Baxter, 2010; Micromedex, 2018; Tatro, 2009) for the most frequent (top ten) interacting drug pairs. Patients with the interaction (aspirin and furosemide), presented with shortness of breath (SOB), pedal edema, increased blood pressure (BP), orthopnea, chest pain \& generalized edema; raised levels of blood urea nitrogen (BUN) and serum creatinine. In patients with the interacting drug pair (aspirin and clopidogrel), SOB, orthopnea, nausea, anemia, epistaxis and melena; reduced hemoglobin, raised international normalized ratio (INR), prothrombin time (PT) and activated partial thromboplastin time (APTT) were observed. In patients presenting with another interaction, i.e. aspirin and nitroglycerin, the following characteristic features such as hypotension, fever, dizziness, nausea/ vomiting, headache, dyspnea and vertigo; raised BUN, bilirubin and reduced hemoglobin were observed. Impaired renal function was noticed in patients with interactions such as aspirin + spironolactone and aspirin + furosemide. Moreover, an increase in BP was detected in patients encountered with interactions such 
as aspirin + ramipril, aspirin + bisoprolol and ramipril + spironolactone. Whereas, in patients presenting with interactions, i.e. aspirin + nitroglycerin and furosemide + ramipril, a decrease in BP was seen.
Bleeding was observed in patients with interaction, clopidogrel + enoxaparin. Hyperkalemia was observed in patients with drug interacting pairs such as digoxin + furosemide and ramipril + spironolactone.

TABLE VI - Top ten interactions, their documentation, clinical relevance and monitoring/management guidelines

\section{Interactions (n) [Documentation]}

Signs and symptoms (n)
Monitoring, Management

Laboratory investigations (n) guidelines (Micromedex 2017; Baxter 2010; Tatro 2009)

Patients should be monitored for signs of worsening renal function, diuretic efficacy, appropriate effects on blood pressure and high dose aspirin should be avoided.

Patients should be monitored for signs and symptoms of bleeding and close assessment of blood counts. Caution is advised while using this combination, owing its increased risk of thrombotic events, therefore coprescription may be considered carefully.

The combination may benefit the Hypotension (31)

Dizziness (08)

Aspirin+

Nitroglycerin (172) [Good]

Nausea \& Vomiting (06)

Headache (05)

Dyspnea (05)

Vertigo (02)

Basal Crepitations (26) SOB (16)

Aspirin+ Spironolactone (137) [Good]
Hemoglobin: Low

(07), Normal (35)

Platelets Count: Low

(04), High (04)

INR: High (03)

PT: High (02)

APTT: High (02)

Hemoglobin: Low (05), High (01) Platelets: Low (02), Normal (04), High (01)

BUN: Normal (03), High (14)

Bilirubin: Normal (02), High (03)

BUN: Normal (02), High (07)

Serum Sodium: Low (02),

Normal (02), High (01)

Serum Potassium: Normal

(05), High (01)

INR: High (02)

PT: High (01) patients with acute myocardial infarction (AMI). Nevertheless, monitoring for an exaggerated response to nitroglycerin (headache, syncope) and platelet function is advised.

Patients should be monitored for signs of worsening renal function, diuretic efficacy and blood pressure in patients chronically receiving spironolactone and salicylates. The effects of interaction can be reversed by increasing the spironolactone dose.
Orthopnea (08)

Generalized Edema (06)

Chest Pain (06)

Headache (05) 
TABLE VI - Top ten interactions, their documentation, clinical relevance and monitoring/management guidelines

\section{Interactions (n) [Documentation]}

Signs and symptoms (n) Laboratory investigations (n)
Monitoring, Management guidelines (Micromedex 2017;

Baxter 2010; Tatro 2009)
Furosemide+

Ramipril (132)

[Good]

Digoxin+

Furosemide (112)

[Fair]

Aspirin+

Ramipril (101)

[Fair]
Hypotension (26)

Pedal Edema (10)

Dizziness (09)

Generalized Edema (05)

Nausea (03)

Vomiting (02)

Vertigo (01)

Dizziness (05)

Nausea (04)

Vomiting (03)

Headache (02)
BUN: High (10)

Serum Creatinine: Normal (05), High (05)

Serum Sodium: Low (01), Normal (03), High (01)
BUN: Normal (01), High (07) Serum Creatinine: Normal (03), High (04) Serum Potassium: Normal (05), High (03)

The patients with sodium depletion and hypovolemia are at high risk. Closely monitor blood pressure of the patients for a severe hypotensive response for four hours after the initial dose. Temporarily discontinue furosemide and/or the patient should be started at very low dose angiotensin converting enzyme (ACE) inhibitors, particularly in evening; monitor for hypotension, fluid status, and body weight regularly for up to two weeks after dose adjustments.

Frequent monitoring of serum potassium and serum magnesium levels.

Educate patients about the decrease intake of dietary potassium and/or potassium supplements.

Aspirin may result in reduced ramipril effectiveness.

Patient's blood pressure and hemodynamic parameters

Basal Crepitations (19) SOB (12) Cough (06) Chest Pain (03) Pedal Edema (05) Headache (02)
BUN: Normal (01), High (08)

Serum Creatinine: Normal (06), High (03)

Serum Sodium: Low (01), Normal (04), High (01) should be monitored. Consider the following option in case of any adverse effect; (a) aspirin dosage less than $100 \mathrm{mg}$ per day (b) an alternative nonaspirin antiplatelet agent (c) replacing ACE inhibitors with angiotensin receptor blockers.

Pallor (14)

SOB (13)

Clopidogrel+ Enoxaparin (92) [Fair]
Chest Pain (07)

Pedal Edema (04)

Nausea (04)

Melena (01)

Epistaxis (01)
Serum Bilirubin: High (05)

Hemoglobin: Low

(02), Normal (01)

INR: High (02)

PT: High (01)

APTT: High (01)
Prompt evaluation for signs or symptoms of bleeding is advised. Additionally, if possible discontinue the antiplatelet agent prior to initiating a low molecular weight heparins (LMWHs). 
TABLE VI - Top ten interactions, their documentation, clinical relevance and monitoring/management guidelines

\section{Interactions (n) [Documentation]}

Signs and symptoms (n)
Laboratory investigations (n)
Monitoring, Management guidelines (Micromedex 2017; Baxter 2010; Tatro 2009)
Ramipril+ Spironolactone (80) [Good]

\author{
Increased Blood Pressure (06) \\ Cough (05) \\ Hyperkalemia (05)
}

BUN: High (05)

Serum Potassium: High (05) Serum Creatinine: Normal (03), High (01)

Patients should be monitored for persistent elevations of serum potassium, especially in patients with renal dysfunction or diabetes and the elderly; which can lead to severe arrhythmias and death. In patients receiving co-prescription (ramipril \& spironolactone); spironolactone may be used 25 $\mathrm{mg}$ daily or on alternate day.

Monitoring of blood pressure is advised. In heart failure, the beta blockers are considered to be narrow therapeutic index. Concomitant use of NSAIDs should generally be avoided in patients with heart failure.

Aspirin+

Bisoprolol

(79)

[Good]
SOB (10)

Increased Blood Pressure (07)

Chest Pain (05)

Pedal Edema (04)

Headache (03)
BUN: Normal (01), High (08)

Serum Creatinine: Normal

(06), High (03)

INR: High (01)

PT: High (01)

APTT: High (01)

$\mathrm{SOB}=$ shortness of breath; BUN = blood urea nitrogen; INR = international normalized ratio; PT = prothrombin time; APTT = activated partial thromboplastin time; ACE = Angiotensin converting enzyme; LMWHs = low molecular weight heparin; NSAIDs $=$ Nonsteroidal anti-inflammatory drugs.

\section{DISCUSSION}

This study presents the frequency, nature of pDDIs and associated clinical outcomes in LVF patients. The overall prevalence of pDDIs identified in our study is higher compared with other studies conducted on patients with HF (88\%) (Roblek et al., 2014; Straubhaar, Krahenbuhl, Schlienger, 2006). This inconsistency may be attributed to one or more of the following reasons: variable study design, nature of study subjects, drug prescribing patterns, and DDIs screening tools. Furthermore, 94\% prevalence reported in our study is higher than studies conducted in other diseased patients, such as acquired immune deficiency syndrome (overall prevalence of pDDIs = 40\%) (Marzolini et al., 2010), bone marrow transplant (60\%) (Guastaldi et al., 2011), prostate cancer (52\%) (Jamani et al., 2016) and in different hospital wards like internal medicine (53\%) (Ismail et al., 2013b), oncology (46\%) (van Leeuwen et al., 2013), pediatrics (26\%) (Ismail et al., 2013a) and psychiatry (65\%) (Ismail et al., 2012). In the majority of hospitals in the developing world, the clinical pharmacy department and DDIs screening programs do not exist, which render the patients prone to irrational use of medicines. Lack of facilities, poor access to available health care facilities, and burdened health professionals also contribute to the underprivileged health management and treatment. In such situations, drug related problems, including pDDIs remain a major issue (Ismail et al., 2013b). Therefore, present results require proper consideration of pDDIs particularly in patients with LVF. Different evidence based strategies are recommended to manage this problem such as screening of medication profiles for pDDIs with the use of computerized based screening programs (Moura 
et al., 2012), clinical pharmacist participation in patient evaluation for pDDIs (Roblek et al., 2016), laboratory test assessment for pDDIs related ADRs (Geerts et al., 2009), and health professional education about pDDIs (Riechelmann et al., 2007).

Severity of pDDIs remains a mainstay to be considered for proper evaluation and management of pDDIs. In this study major $(n=1405)$ and moderatepDDIs $(n=1365)$ were most frequent; likewise, pDDIs with good $(n=1349)$ and fair $(n=1291)$ scientific evidence were most common. These findings are inconsistent with other studies conducted in different conditions and specialties or wards. A Swiss study reported moderate-pDDIs (65\%) as most frequent (Straubhaar, Krahenbuhl, Schlienger, 2006). Likely, another study conducted in Slovenia reported moderate-pDDIs $(92 \%)$ to be most prevalent (Roblek et al., 2014). In oncology, moderate-pDDIs (83\%) (van Leeuwen et al., 2013) are more prevalent, while in pediatrics (26\%), moderate-pDDIs and good type of documented evidence was reported for majority of pDDIs (Ismail et al., 2013a). However, in internal medicine, moderate-pDDIs $(63 \%)$ and good $(61 \%)$ type of documentary evidence pDDIs were mostly observed (Ismail et al., 2013b). Our findings suggest that patients with LVF are at higher risk of clinically significant interactions. Therefore, it is crucial for health care professionals to identify and classify pDDIs. It is important for clinical management of pDDIs and minimizing their risk while adopting prophylaxis measures for prevention.

Patients with HF usually receive polypharmacy for their proper management. There is a positive relation between number of prescribed medicines and risks of pDDIs (Guastaldi et al., 2011; Ismail et al., 2012; Marzolini et al., 2010). Significant association of exposure to $>6$ pDDIs with hospital stay and number of prescribed medicines is in accordance with other studies (Ismail et al., 2017; Ismail et al., 2013a; Ismail et al., 2013b). We have calculated odds ratio of exposure to $>4$ major-pDDIs separately. The significant relation of major-pDDIs with gender and prescribed medicines are consistent with other studies (Ismail et al., 2017; Ismail et al., 2013a, Ismail et al., 2013b; van Leeuwen et al., 2013). Based on these results, patients with LVF are at considerable risk of major-pDDIs due to polypharmacy and prolonged hospital stay. Therefore, such patients must be screened for pDDIs, preferably through a Computer-based DDIs screening tool. Such screening is crucial before prescribing and administering drugs in order to identify problems in advance to prevent and manage them accordingly.

List of the most frequently occurring pDDIs, especially contraindicated, major and moderate pDDIs are of prime importance for physicians and pharmacists. It can be used for selective screening of DDIs. Patients with these interactions may be given special attention and their therapy may be closely monitored for all potential adverse outcomes.

Clinical relevance specifies the potential adverse outcomes associated with pDDIs on the basis of patients' clinical characteristics and various laboratory test results. This study strengthens the fact that the screening of medication profiles for the presence of pDDIs should be done. Other studies have highlighted the same issue (Cruciol-Souza, Thomson, 2006a; Zwart-van Rijkom et al., 2009). Such studies will guide the clinicians and other health care professionals regarding the assessment and management of these DDIs in LVF patients.

Following are the potential limitations of this study. A number of DDI resources (Pharmavista, Lexi-interact and Drug Interaction Facts) are available (Vonbach et al., 2008) and differences exist among the available screening tools (Kheshti, Aalipour, Namazi, 2016). However, we used a single software (Micromedex Drug-Reax), which provides complete and reliable information, for the screening of pDDIs. Furthermore, we identified some predictors that increase the risk for pDDIs. Further, studies can be designed to investigate the contribution of other factors such as use of a specific class of drugs, multiple prescribers, a specific diagnosis and type and number of comorbid illnesses.

\section{CONCLUSION}

This study shows high prevalence of pDDIs in LVF patients. Majority of interactions were of major severity, followed by moderate severity interactions. Patients of male gender and greater number of prescribed medicines were more exposed to major-pDDIs. List of most frequently identified major and moderate interactions will be helpful in screening medication therapies for pDDIs. Monitoring of all clinically relevant features (signs, symptoms and laboratory/diagnostic tests) with proper consideration of various predictors is recommended to prevent and manage clinical outcomes of these interactions. 


\section{ACKNOWLEDGEMENT}

The authors would like to thank the administration, consultants and all other staff of the two hospitals for their cooperation in this study.

\section{REFERENCES}

Alvarez PA, Putney D, Ogunti R, Puppala M, Ganduglia C, Torre-Amione G, et al. Prevalence of in-hospital nonsteroidal antiinflammatory drug exposure in patients with a primary diagnosis of heart failure. Cardiovasc Ther. 2017;35(3):e12256.

Baxter K. Stockley's Drug Interactions. 9th ed. London, Chicago: Pharmaceutical Press; 2010.

Bykov K, Gagne JJ. Generating Evidence of Clinical Outcomes of Drug-Drug Interactions. Drug Saf. 2017;40(2):101-3.

Cruciol-Souza JM, Thomson JC. A pharmacoepidemiologic study of drug interactions in a Brazilian teaching hospital. Clinics (Sao Paulo). 2006a;61(6):515-20.

Cruciol-Souza JM, Thomson JC. Prevalence of potential drug-drug interactions and its associated factors in a Brazilian teaching hospital. J Pharm Pharm Sci. 2006b;9(3):427-33.

Geerts AF, De Koning FH, De Smet PA, Van Solinge WW, Egberts TC. Laboratory tests in the clinical risk management of potential drug-drug interactions: a cross-sectional study using drug-dispensing data from 100 Dutch community pharmacies. Drug Saf. 2009;32(12):1189-97.

Go AS, Mozaffarian D, Roger VL, Benjamin EJ, Berry JD, Blaha MJ, et al. Heart disease and stroke statistics-2014 update: a report from the American Heart Association. Circulation. 2014;129(3):e28.

Guastaldi RB, Reis AM, Figueras A, Secoli SR. Prevalence of potential drug-drug interactions in bone marrow transplant patients. Int J Clin Pharm. 2011;33(6):1002-9.

Ismail M, Aziz S, Noor S, Haider I, Shams F, Haq I, et al. Potential drug-drug interactions in pediatric patients admitted to intensive care unit of Khyber Teaching Hospital, Peshawar, Pakistan: A cross-sectional study. J Crit Care. 2017;40(2017):243-50.

Ismail M, Iqbal Z, Khan MI, Javaid A, Arsalan H, Farhadullah, et al. Frequency, levels and predictors of potential drug-drug interactions in pediatrics ward of a teaching hospital in Pakistan. Trop J Pharm Res. 2013a;12(3):401-6.

Ismail M, Iqbal Z, Khattak MB, Javaid A, Khan MI, Khan TM, et al. Potential Drug-Drug Interactions in Psychiatric Ward of a Tertiary Care Hospital: Prevalence, Levels and Association with Risk Factors. Trop J Pharm Res. 2012;11(2):289-96.

Ismail M, Iqbal Z, Khattak MB, Khan MI, Arsalan H, Javaid A, et al. Potential drug-drug interactions in internal medicine wards in hospital setting in Pakistan. Int $\mathrm{J}$ Clin Pharm. 2013b;35(3):455-62.

Jamani R, Lee EK, Berry SR, Saluja R, DeAngelis C, Giotis A, et al. High prevalence of potential drug-drug interactions in patients with castration-resistant prostate cancer treated with abiraterone acetate. Eur J Clin Pharmacol. 2016;72(11):1391-9.

Kheshti R, Aalipour M, Namazi S. A comparison of five common drug-drug interaction software programs regarding accuracy and comprehensiveness. J Res Pharm Pract. 2016;5(4):257.

Ledwidge M, Travers B, Ryder M, Ryan E, McDonald $\mathrm{K}$. Specialist care of heart failure improves appropriate pharmacotherapy at the expense of greater polypharmacy and drug-interactions. Eur J Heart Fail. 2004;6(2):235-43.

Marzolini C, Elzi L, Gibbons S, Weber R, Fux C, Furrer H, et al. Prevalence of comedications and effect of potential drugdrug interactions in the Swiss HIV Cohort Study. Antiviral therapy. 2010;15(3):413-23.

Meid AD, von Medem A, Heider D, Adler J-B, Günster C, Seidling HM, et al. Investigating the additive interaction of QT-prolonging drugs in older people using claims data. Drug saf. 2017;40(2):133-44.

Metra M, Teerlink JR. Heart failure. Lancet. 2017;390(10106):1981-95.

Micromedex. Micromedex Drug-Reax ${ }^{\circledR}$ (Truven Health Analytics, Greenwood Village, Colorado, USA) [cited 2018 Jan 30]. Available from: http://www.micromedexsolutions.com.

Moura CS, Prado NM, Belo NO, Acurcio FA. Evaluation of drug-drug interaction screening software combined with pharmacist intervention. Int J Clin Pharm. 2012;34(4): $547-52$.

Riechelmann RP, Tannock IF, Wang L, Saad ED, Taback NA, Krzyzanowska MK. Potential drug interactions and duplicate prescriptions among cancer patients. J Natl Cancer Inst. 2007;99(8):592-600.

Roblek T, Deticek A, Leskovar B, Suskovic S, Horvat M, Belic A, et al. Clinical-pharmacist intervention reduces clinically relevant drug-drug interactions in patients with heart failure: A randomized, double-blind, controlled trial. Int J Cardiol. 2016;203(2016):647-52. 
Prevalence, predictors and outcomes of potential drug-drug interactions in left ventricular failure: considerable factors for quality use of medicines

Roblek T, Trobec K, Mrhar A, Lainscak M. Potential drugdrug interactions in hospitalized patients with chronic heart failure and chronic obstructive pulmonary disease. Arch Med Sci. 2014;10(5):920-32.

Roblek T, Vaupotic T, Mrhar A, Lainscak M. Drug-drug interaction software in clinical practice: a systematic review. Eur J Clin Pharmacol. 2015;71(2):131-42.

Rosenkranz S, Gibbs JS, Wachter R, De Marco T, VonkNoordegraaf A, Vachiery JL. Left ventricular heart failure and pulmonary hypertension. Eur Heart J. 2016;37(12): 942-54.

Sanchez-Fidalgo S, Guzman-Ramos MI, Galvan-Banqueri M, Bernabeu-Wittel M, Santos-Ramos B. Prevalence of drug interactions in elderly patients with multimorbidity in primary care. Int J Clin Pharm. 2017;39(2):343-53.

Stough WG, Patterson JH. Role and Value of Clinical Pharmacy in Heart Failure Management. Clin Pharmacol Ther. 2017;102(2):209-12.
Straubhaar B, Krahenbuhl S, Schlienger RG. The prevalence of potential drug-drug interactions in patients with heart failure at hospital discharge. Drug Saf. 2006;29(1):79-90.

Tatro DS. Drug Interaction Facts. 1st Edition ed: Lippincott Williams \& Wilkins; 2009.

van Leeuwen RW, Brundel DH, Neef C, van Gelder T, Mathijssen RH, Burger DM, et al. Prevalence of potential drug-drug interactions in cancer patients treated with oral anticancer drugs. Br J Cancer. 2013;108(5):1071-8.

Vonbach P, Dubied A, Krähenbühl S, Beer JH. Evaluation of frequently used drug interaction screening programs. Pharm World Sci. 2008;30(4):367-74.

Zwart-van Rijkom JE, Uijtendaal EV, ten Berg MJ, van Solinge WW, Egberts AC. Frequency and nature of drugdrug interactions in a Dutch university hospital. Br J Clin Pharmacol. 2009;68(2):187-93.

Received for publication on $27^{\text {th }}$ April 2018 Accepted for publication on $15^{\text {th }}$ September 2019 